2019-05

\title{
Grievance handling in Egyptian hotels and travel agencies
}

\section{Elbaz, AM}

http://hdl.handle.net/10026.1/13824

10.1016/j.annals.2019.04.012

Annals of Tourism Research

Elsevier Masson

All content in PEARL is protected by copyright law. Author manuscripts are made available in accordance with publisher policies. Please cite only the published version using the details provided on the item record or document. In the absence of an open licence (e.g. Creative Commons), permissions for further reuse of content should be sought from the publisher or author. 


\title{
Grievance Handling in Egyptian Hotels and Travel Agencies
}

\author{
Ahmed Mohamed Elbaz \\ ahmed.elbaz@fth.usc.edu.eg \\ Mohamed Yacine Haddoud \\ mohamed.haddoud@plymouth.ac.uk \\ Adah-Kole Emmanuel Onjewu \\ ac6961@ coventry.ac.uk \\ Hany Hosny Sayed Abdelhamied
}

\begin{abstract}
The literature on grievance handling is a highly developed body of work. Yet, findings on the most effective means of conflict management remain inconclusive. To address this gap, the current study adopts a novel fuzzy-set configuration approach using a sample of 857 employees in Egyptian tourism and hospitality. Consistent with the view that grievance handling is a complex issue that is responsive to "equifinal" solutions, the inherent findings establish the existence of two effective but alternative grievance handling techniques. These two styles were found to differ in terms of education, experience, age, gender and the nature of the organisation. The findings hold important implications for theory and practice.
\end{abstract}

\section{INTRODUCTION}

An unstable political climate propelled by the revolution in early 2011, a military takeover in 2013, and a series of high-profile airline disasters beginning in 2015 have severely undermined the attractiveness of an industry that constituted 11.4\% of Egypt's GDP in 2015 (Michaelson, 2016). Therefore, there is an urgent need to revitalise and stimulate the Egyptian tourism sector (Attallah, 2015). Despite a 55.1\% increase in the number of tourists between 2016 and 2017 amounting to 8.5 million visitors (Egypt Today, 2018), Egypt's recovery still lags behind the 14 million visitors it welcomed in 2010 (World Tourism Organisation, 2018). 
Among several possible solutions to revive visitor numbers, the exclusive and primary focus of this paper is on the job satisfaction and high performance of employees at the fore and centre of Egypt's tourism recovery strategy. Indeed, to be competitive, tourism managers evince a peculiar curiosity about employees' feelings and grievances (Simons \& Enz, 1995). This curiosity is manifest because cooperation, rather than conflict, is needed to optimise the overall governance of the tourism entity (Lee, Riley \& Hampton, 2009). Both practically and theoretically, conflicts and the subsequent need for grievance handling in the Egyptian context border on the personal and departmental relationships at work (Kattara \& El-Said, 2013). For instance, owing to longstanding cultural traditions defining male-female roles, Kattara (2005, p. 251) contends in a study of Egyptian hotel managers that, firstly, 'interdepartmental cooperation is made easier when male managers rather than female managers are involved'. Secondly, female managers 'find it difficult to give orders to male subordinates' and lastly, 'female managers are not as appreciated as male managers'. Therefore, when gender and other variables are factored, tourism managers in Egypt have an imperative to be proactive in managing conflicts because, left unresolved, they result in a range of negative outcomes including reduced work performance, psychological distress and burnout among staff (Labrague, Al Hamdan \& McEnroe-Petitte, 2018). Hence, increasingly, managers require tools to manage stress within the workforce to mitigate the adverse impact on operations (Messarra, Karkoulian \& El-Kassar, 2016).

Daud, Isa, Nor \& Zainol (2013) define grievance as a formal complaint by an employee or employees ensuing from dissatisfaction in relations between themselves and their supervisors. It is fundamentally "the discord that arises when the goals, interests, or values of different individuals or groups are incompatible, and those individuals or groups block or thwart one another's attempts to achieve their objectives" (Pines et al., 2014, p. 880). There is an understanding that employee dissatisfaction in the line of duty is a natural, 
functional and inherent phenomenon that results in conflicting viewpoints, inefficient use of resources and poor service delivery (Bean, 2004). Moreover, as these perils are perceptibly more manifest in labour-intensive environments like tourism and hospitality, managers' capacity to handle grievances in this environment is of critical importance to the quality of employees' experiences and work life (Friedman, Tidd, Currall \& Tsai, 2000). In fact, grievances may be mishandled to the extent that positive employee relations and organisational productivity are undermined (Chan, Huang \& Ng, 2008). Particularly, proactive conflict management is essential to motivate frontline staff who directly interact with and influence tourists' satisfaction (Mlozi and Pesämaa, 2013). Also, in destinations like Egypt, social relations is a key determinant of service quality (Yolal, Chi \& Pesämaa, 2017).

In spite of studies by Chan et al. (2008), Gunkel et al. (2016), Ayub et al. (2017), Brummer et al. (2017) and Zhang and Wei (2017) on grievance handling styles, a definitive and optimal grievance handling approach has eluded the literature. In this vacuum, conflicting views persist on the efficacy of known grievance handling styles (Isa \& Noor, 2011). There is also a narrow-minded search and desire for a single, universal grievance handling approach (Van de Vliert, Nauta, Giebels \& Janssen, 1999). Taking a cue from most management phenomena, grievance handling is a subjective and complex concept that will command a range of flexible approaches from managers (Nayak, Sahoo \& Mohanty, 2017; Labrague et al., 2018). Here, the complexity is driven by the existence of multiple grievance handling combinations influencing employee behavior. It appears that previous studies have neglected this view even though there have been noteworthy attempts to empirically address the aforementioned complexity using regression-based techniques (e.g. Munduate, Ganaza, Peiro and Euwema, 1999; Van de Vliert., 1999). Conversely, more robust approaches are needed to capture complex linkages in grievance handling to answer the enduring question: Which combination of grievance handling styles is likely to increase employees' job 
satisfaction? Addressing this question is the core purpose of this paper. Existing studies have done as much as explore the characteristics and attributes of employees in tourism (Baum, 2015) and determine productivity challenges (Li, Joppe and Meis, 2016; Liu, Law and Zhong, 2017). Methodologically, studies by Baum (2015) and Liu, Law and Zhong (2017) were conceptual in their techniques while Li, Joppe and Meis' (2016) investigation applied multivariate regression analysis.

Accordingly, to make a novel contribution to the literature, the current study applies a novel configuration approach using fuzzy-set Qualitative Comparative Analysis (fsQCA) to capture complex associations in the grievance handling process in Egyptian tourism. Introduced by Ragin (2000), fsQCA is a set-theoretic approach to analyse multiple configurations (if any) associated to a given outcome (Fiss, Sharapov and Cronqvist, 2013; Ordanini, Parasuraman and Rubera, 2014). Its use in this paper will be adequate for capturing the combined effects of various grievance handling styles on job satisfaction. This is particularly relevant because grievance handling is a complex behaviour (Nayak et al., 2017), and complex behaviours compel a blend of iterative methods rather than a single approach (Van de Vliert, Euwema, and Huismans, 1995; Van de Vliert, 1997; Munduate et al., 1999). Here, fsQCA goes beyond the identification of single predictors and is able to capture various configurations driving a behaviour (Fiss et al., 2013). Hence, by comparison, fsQCA is preferred to regression analysis because it 'leads to a fuller understanding of the conditions under which the outcome occurs' (Vis, 2012, p. 1). Added to this, the principle of 'equifinality' [the presence of various solutions for a single outcome] is pertinent to grievance handling (Daud et al., 2013). Thus, identifying multiple solutions will offer more options to managers and decision makers in grievance handling situations.

To this end, this paper appeals to the human resource in tourism literature by addressing complexity issues in grievance handling. It also offers an improved understanding 
of the effects of grievance handling styles on job satisfaction in Egypt's tourism sector. As things stand, the contemporary human resource in tourism literature focuses either on the determinants of conflict handling styles adopted (e. g. Saeed et al., 2014; Gunkel et al., 2016; Zhang and Wei, 2017; Abbasi et al., 2018), or their impact on job satisfaction through a neteffect approach (Montoro-Rodriguez and Small, 2006; Chan et al., 2008; Chen et al., 2012). Unfittingly, neither of the aforementioned approaches suffice to capture the complexities of grievance handling between employees and managers.

To proceed, the current study is set in Egypt where tourism is an economic backbone and key source of foreign exchange. Egypt is also the second most popular tourist destination in the Middle-East (Brown and Osman, 2017). In 2017, tourism generated 7.3\% of Egypt's gross domestic product (WTTC, 2017) but, notwithstanding the volume of tourism-centric research in the country, evidence from this region remains scarce in comparison to European and North American destinations. To this end, a recent review on conflict management styles called for cross-cultural studies to uncover the international dynamics of this issue (Labrague and McEnroe-Petitte, 2017). Therefore, this paper makes a contextual contribution with new evidence from the Middle-East.

\section{CONCEPTUAL FRAMEWORK}

\section{1. $\quad$ Approaches to Handling Grievances}

In hospitality, the high dependence of jobs on employees' interaction means that the potential for conflict through disputes and disagreement is greater (Salem, 2015). These conflicts can arise from highly demanding tasks and lack of organisational support (Yang, Wan and $\mathrm{Fu}, 2012$ ). Handling different patterns of grievance requires constructive techniques to stabilise the workforce and optimise productivity. There is evidence that poorly handled grievance results in low morale, poor performance, absenteeism, tardiness and an increased 
turnover intention among employees. To avoid these pitfalls, Thomas and Schmidt (1976) and Rahim (1983) proposed a model with two dimensions to settle employees' grievances. The dimensions are concern for self and concern for others. Firstly, concern for self measures the degree (high or low) to which individuals try to fulfil their own interests. Secondly, concern for others measures the degree (high or low) to which individuals exert themselves to address others' interests. Significantly, both concern for self and concern for others underscore employees' motivation in conflict situations (Rubin and Brown, 1975). Hence, analyses into behaviours exuded in concern for self and others now inform five widely recognised approaches of handling interpersonal conflict including integrating, obliging, compromising, dominating and avoiding (Ayub, AlQurashi, Al-Yafi and Jehn, 2017; Gunkel, Schlaegel and Taras, 2016). Chan et al. (2008) contend that integrating, obliging and compromising are cooperative styles while dominating and avoiding are uncooperative styles of grievance management. These are further explained:

\subsubsection{Integrating Approach}

The integrating approach is a blend of advancing one's interests as well as those of others during conflict. It is centered on employees' willingness to cooperate through an openness in sharing knowledge, making contingency plans and collective problem-solving for resolutions that are acceptable to both parties (Rahim and Magner, 1995). This approach provides opportunities for opposing sides to see things from divergent points of view (Daud et al., 2013). Messarra et al. (2016) consider this approach as a win-win affair where both parties resolve conflict by maximising mutual gains.

\subsubsection{Obliging Approach}

Also known as the accommodating style (Messarra et al., 2016), the basis for an obliging approach is low concern for self. Using this approach, individuals promote shared 
values and commonalities that satisfy the interests of other parties (Gunkel et al., 2016). The benefit of an obliging style is that it shortens the distance in opinions by clarifying revealing similarities in one's and others' opinions (Yuan, 2010). However, obliging is only appropriate for situations where one party is indiscreet about their agenda and the other party has fundamental concerns that need addressing (Yuan, 2010). To this end, it is vital for individuals to minimise their differences with other parties to adopt an obliging style. This style can therefore be considered as a lose-win interaction (Messarra et al., 2016).

\subsubsection{Compromising Approach}

A compromising style requires a degree of self-interest along with concession for the other conflicting party. It seeks a middle-ground and a moderation of concerns expressed by self and others (Rahim, 2002). The benefit of compromising is that parties are availed the opportunity to understand, give-and-take and compare points of view to reach a satisfactory decision for both parties (Rahim and Magner, 1995). Unlike the integrating style, a compromising approach does not fully satisfy both parties. Rather, it requires all parties to concede some ground in order for conflicts to be resolved in a no-win/no-lose manner (Messarra et al., 2016). This approach is desirable for goal congruence in complex issues where two dominant parties are involved (Thomas, Fann and Schaubhut, 2008).

\subsubsection{Avoiding Approach}

The key feature of the avoidance style is individuals' low concern for self as well as for others during conflict (Rahim and Magner, 1995). Its indicators are withdrawal from encounters of tension when, for example, employees reject the completion of tasks required by supervisors. Withdrawal is not always manifest through outright intransigence but may be tactfully done to avoid expected problems or delay their unravelling (Thomas and Kilmann, 1974). Avoidance is mostly observed in situations where opposing views are trivial or when 
individuals anticipate an adverse response from the other party (Lee, Riley \& Hampton, 2010). Messarra et al. (2016) consider this a lose-lose interaction.

\subsubsection{Dominating Approach}

In a dominating approach, entities show a reduced concern for others but a high concern for self as they impose their views on others (Daud et al., 2011). This style is typically considered a win-lose interaction where only one winner emerges (Messarra et al., 2016). The symptoms of this approach are authority orientation and a competitive mindset. The benefit of domination is that it expedites decision-making by authority holders (Rahim, 2002). This approach reflects a reduced concern for others and a high concern for self and manifests in coercing one's perspective over others (Daud et al., 2011). Accordingly, Thomas and Kilmann (1974) describe the dominating technique as an authority-oriented approach or competition-based style. However, domination bodes well for scenarios where urgent decisions need to be made by managers (Rahim, 2002).

\section{GRIEVANCE HANDLING STYLES AND JOB SATISFACTION:}

There is substantial evidence that grievance handling methods have a direct relationship with levels of job satisfaction (Friedman et al., 2000; Montoro-Rodriguez and Small, 2006; Chan et al., 2008; Chen et al., 2012). Informed by findings from studies in various settings, Rahim and Buntzman (1989) posited that employees' perception of superiors' integrating style has a positive influence on their satisfaction. In the same vein, Alexander (1995) reported a positive link between collaborative and compromising grievance handling with job satisfaction in the education sector. In contrast, Friedman et al. (2000) note that avoidance and obliging grievance handling have a direct relationship with work stress. For nurses, the evidence is that cooperative grievance handling positively promotes job 
satisfaction (Montoro-Rodriguez and Small, 2006). In fact, Lee (2009) concludes that employees are more satisfied when exposed to integrating, compromising, and obliging styles, as opposed to dominating and avoiding styles. Equally, Chen et al. (2012) confirm that integrating and compromising behaviours are positively related to job satisfaction, whereas dominating and obliging styles have no influence.

Furthermore, empirical evidence in international studies support the foregoing notion. In Turkey, Erkutlu and Chafra (2015) found that a cooperative style is positively correlated with organisational identification. In Hong Kong, undergraduate nursing students have shown a preference for the integrating style in managing conflicts with clinical supervisors, while the dominating style was considered the least preferred (Chan et al., 2014). Similarly, for Chinese users of networking sites, cooperative styles were found to positively affect users' satisfaction, as opposed to uncooperative styles (Zhang et al., 2017). A recent study in Malaysia reported that cooperative and avoiding conflict handling styles positively affect team performance (Tabassi et al., 2017). In Germany, Brummer, Herbes, and Gericke (2017) concluded that an integrative approach was often preferred regardless of its time-consuming nature, whereas the remaining four handling styles played a trivial role. In Saudi Arabia, integrating was the most preferred style adopted by employees followed by avoiding, compromising, obliging and then dominating (Ayub et al., 2017). In contrast, a few studies reported avoiding (Pines et al., 2012; Hartman and Crume, 2014) and dominating styles (Waite and McKinney, 2014) as the preferred options. Lastly, once more in China, both collaborating and compromising styles were found to generate a feeling of fulfilment and reward (Meng, Yu, Ma and Yang, 2018).

\section{GRIEVANCE HANDLING STYLES: A COMPLEX CONTINGENCY LENS}


The underlying philosophy in this study is the contingency theory. In principle, the theory posits that the effectiveness of HR practices is subject to internal and external conditions (Chow and Liu, 2009). In other words, the link between HR practices and performance depends on a number of proximate and remote factors and that no single best practice can resolve. Rather, in contingency theory, optimal strategies are shaped by dynamic and situational techniques. To this extent, Yuan (2010) argues that management solutions should be proffered circumstantially and contextually. More pertinently, Delery and Doty (1996) explain that a contingency perspective is a complex approach that reconciles interactions rather than the simple linear relationships evoked in other theories.

For grievance management, a contingency approach implies that the link between grievance handling styles and employees' satisfaction is a complex relationship shaped by various external factors. Therefore, through the contingency lens, we expect that multiple handling strategies could exist and depend on subjective factors. The current paper considers the effectiveness of grievance handling styles to be a complex and unsettled issue because managers exude a blend of approaches rather than a single approach (Van de Vliert, Euwema and Huismans, 1995; Van de Vliert, 1997; Munduate et al., 1999). Conflicts are fundamentally complex so the methods for their resolution mirror this complexity with the use of cooperative styles for certain aspects and dominating styles for others (Van de Vliert et al., 1999). Rahim (1992) is of the same mind and asserts that a dominating style is appropriate for urgent and unpopular decisions while flexible styles are reserved for occasions to merge insights and navigate negative feelings. In fact, an integrating style could be resource and time consuming and, therefore, ill-suited to resolve low-priority conflicts (Messarra et al., 2016).

From the above, the inclination to adopt certain grievance handling styles to the exclusion of others is an area yet to be clarified in the literature (Munduate et al., 1999). As 
previous studies indicate that a single style is more effective to achieve sought outcomes (Van de Vliert et al., 1999), the narrowmindedness that detracts from the lived reality of individuals adopting various approaches to resolve conflicts within the same interaction ought to be challenged (Nicotera, 1994). Thus, "it is about time that conflict handling is conceptualized as a complex pattern of behavioral components rather than as a pure and single behaviour" (Van de Vliert et al., 1999: 153). Also, the combination of various grievance handling techniques to resolve conflicts constitutes the rule and not the exception for effectiveness (Rubin, Pruitt and Kim 1994; Van de Vliert et al., 1999). For example, the risks of a dominating approach, such as increased costs and damaged relations, can only be offset by counteracting them with a cooperative approach. For this reason, McKersie and Cutcher-Gershenfeld (2009) argue that increased efficiency and minimized stagnation are two benefits of combining a dominating and cooperative approach. In a recent study based on observation data, Brummer et al. (2017, p. 196) asserted that "it was common to see participants switch conflict handling styles during conflict episodes to get a desired outcome". They further explained that switching styles mostly occurs when the first style turns out to be ineffective.

In order to probe the prevailing assumption that grievance handling styles are mutually isolated determinants of job satisfaction, an investigation into the optimum combination of grievance handling approaches will develop the literature vis-à-vis the complexity of such behaviours. Informed by this review, the present study seeks to address the following propositions:

Proposition 1: The adoption of a single grievance handling style such as integrative style, may be necessary, but not sufficient for predicting high job satisfaction.

Proposition 2: A configuration of grievance handling styles is more likely to enhance job satisfaction, than the adoption of a single approach. 


\section{METHOD}

A sample of 857 frontline employees in tourism and hospitality SMEs provided the data for this study. The paper-based survey was distributed in December 2017 with the support of three research assistants. Both small and medium sized hotels (SMHs) and travel agencies were included in the sample because, according to Abou-shouk et al. (2013), the tourism industry is largely dominated by SMEs. Awang, Aziz and Samdin (2015) define SMHs as hotels with a rating of 3 stars and below, with 50 rooms or less, encompassing budget hotels, motels and small resorts. A non-probability convenience sampling technique was adopted in this study. Despite the generalisability and representativeness issues that are often associated with this type of sampling, it remains prevalent in studies involving small businesses (Coviello and Jones 2004; Ahl, 2006). This is mainly due to the challenging nature of small business studies (Jensen and Luthans 2006), which is accentuated in this case with the difficulties of the Egyptian context. Coviello and Jones (2004) support that nonprobability sampling can provide robust data when high participation levels are achieved.

Based on data from the OECD database (2016), we estimate that in 2015 there were approximately 189,000 employees in accommodation services (including large entities ${ }^{1}$ ) and 63,000 employees in travel agencies in Egypt. Following Saunders et al.'s (2016) guidance suggesting a sample of 370-384 (5\% error margin) for populations of this size, we distributed 600 questionnaires to frontline hotel employees and travel agency staff respectively, expecting a 50\% return. For hotel staff, 327 copies were collected, of which 306 were valid and usable, while 21 were judged invalid. As for travel agencies, 569 responses were received, of which 551 were valid and usable; 18 were considered invalid. Overall, across SMHs and travel agencies, 896 copies were collected but only 857 were usable while 39 were unusable due to missing data.

\footnotetext{
${ }^{1}$ No data were available for number of employees in small hotels
} 
The sample characteristics (see Table 1) indicated that frontline employees were mostly youths between 26 and 35 years of age (47\%), followed by the 36 - 45 age group (30.7\%). As for gender, a considerably higher percentage of males were documented (approximately $78.9 \%$ ) as is common in the Middle East with more men participating in the wider economy than women. To explain this trend, Nazier and Ramadan (2016, p. 2) assert that "the Egyptian women labour force participation rate is very low, hovering "between" $20 \%$ to $25 \%$, compared to a global average of $52 \%$ during the 2000 s". This trend was also reflected in the European Training Foundation (2010) survey that reported a mere 10\% participation of women in the Egyptian economy. More recently, the Egyptian Statistical Yearbook (2018) indicated a female participation rate of $16 \%$.

Table 1: Sample Characteristics

\begin{tabular}{|l|l|}
\hline Characteristics & Percentage \\
\hline Gender & \\
\hline Male & 77.1 \\
\hline Female & 22.9 \\
\hline Age group & \\
\hline 18-25 Years & 12.3 \\
\hline 26-35 Years & 47.0 \\
\hline 36-45 Years & 30.7 \\
\hline 46-55 Years & 9.2 \\
\hline More than 55 Years & 0.8 \\
\hline Educational level & \\
\hline Bachelor degree & 69.7 \\
\hline Diploma & 11.7 \\
\hline Master's Degree & 16.2 \\
\hline Doctoral Degree & 0.6 \\
\hline Others & 1.9 \\
\hline Work Experience & \\
\hline Less than 5 Years & 31.2 \\
\hline From 5-10 Years & 33.3 \\
\hline From 11-15 Years & 26.1 \\
\hline More than 15 Years & 9.5 \\
\hline Working place & \\
\hline Hotels & 35.7 \\
\hline Travel agency & 64.3 \\
\hline
\end{tabular}




\section{MEASURES}

In the current paper, six constructs were measured including the integrating, obliging, dominating, avoiding and compromising styles, as well as job satisfaction. All latent variables were estimated using multiple items on a 5-point Likert scale of 1 (strongly disagree) to 5 (strongly agree). To ensure content validity, the items were adopted from previous studies ${ }^{2}$. Here, the specific instrument used to measure the grievance handling styles were adapted from Rahim Organisational Conflict Inventory-II (ROCI-II; Rahim, 1983) (integrating -7 items, obliging -6 items, dominating -5 items, avoiding -6 items, and compromising - 4 items) extracted from Rahim and Magner (1995); Havenga and Visagie (2006) and Daly, Lee, Soutar, and Rasmi (2010). Employee job satisfaction was measured using five items adopted from Judge, Locke, Durham and Kluger (1998) and Bérubé et al. (2007).

\section{ANALYSIS AND RESULTS}

\section{1. $\quad$ fsQCA Analysis and Results}

fsQCA applies a Boolean algebra system to identify a sufficient set of conditions for a sought outcome (Ordanini et al., 2014). fsQCA identifies configurations associated to an outcome (Fiss et al., 2013). fsQCA is able to identify the various "recipes" (if any) associated to an outcome (Ordanini et al., 2014). This is achieved through the inclusion of contrarian cases that deviate from the general trend of the data (Woodside, 2014). It also captures complex asymmetric relationships while accounting for unobserved heterogeneity issues (Wagemann and Schneider, 2010). The software used here was fsQCA.3.0 (Ragin and Davey, 2016)

\footnotetext{
${ }^{2}$ The full list of items is available in the appendix
} 


\subsubsection{Calibration}

In fsQCA analysis, both the conditions (external factors) and the outcome (grievance handling styles and job satisfaction) are first calibrated using fuzzy set scores (Ragin, 2009). The calibration process includes the identification of three values corresponding to three qualitative anchors that represent fuzzy set thresholds of full membership (1), cross over point (0.5) and full non-membership (0) (Ragin, 2009). In the current study, to convert the original Likert scores into fuzzy set scores, scores 1 (strongly disagree), 3 (neutral) and 5 (strongly agree) were denoted to represent non-membership, cross over point and full membership respectively ${ }^{3}$.

\subsubsection{Necessity analysis for high job satisfaction}

A logical necessity analysis highlights the essential individual conditions for a given outcome. These individual conditions would be necessary but not sufficient to produce the outcome (Kent, 2015).

Table 2: Necessity Analysis for High Job Satisfaction

\begin{tabular}{lll}
\hline & Consistency & Coverage \\
\hline Integrating Handling Style & 0.95 & 0.88 \\
Obliging Handling Style & 0.77 & 0.87 \\
Dominating Handling Style & 0.45 & 0.96 \\
Avoiding Handling Style & 0.74 & 0.87 \\
Compromising Handling Style & 0.94 & 0.89 \\
\hline
\end{tabular}

Regarding necessity conditions for high job satisfaction, with a consistency score exceeding the 0.90 threshold, table 2 shows that the integrating and compromising approaches are the two necessary styles associated to high job satisfaction. Inferring Kent (2015), this means that for both integrating and compromising styles, high membership on job satisfaction presupposes high membership on integration and compromise. It can

\footnotetext{
${ }^{3}$ Prior to the calibration process, the validity and reliability of all latent constructs were assessed using a structural equation modelling approach.
} 
therefore be claimed that integrating and compromising handling approaches are necessary but not sufficient to achieve high job satisfaction. This is in line with proposition 1.

\subsubsection{Sufficiency analysis for high job satisfaction}

Results from the fsQCA analysis for high job satisfaction are presented in Table 3 (intermediate solution). For a combination to be valid, the study uses a cut-off value of 19 cases minimum per combination; also known as the frequency threshold. For the consistency threshold, based on a drop in consistency (from 0.97 to 0.89 ), a cut-off of 0.97 was selected. Scores above 0.74 reflect informative solutions (Kent, 2015). However, one solution excluding a necessary condition (compromising style) was excluded from the truth table following the necessity analysis.

Table 3 presents the solutions including the raw consistency measures for each solution. Raw consistency is akin to significance value in hypothesis testing (Woodside and Zhang, 2012). In addition, coverage scores, equivalent to effects size in hypothesis testing (Woodside and Zhang, 2012), are also presented for each solution and condition. These illustrate the proportion of cases explained by a single condition [unique coverage] or the solution [raw coverage] (Ragin, 2009). Finally, the overall solution coverage is also presented to illustrate the extent to which high job satisfaction is determined by identified solutions; this is similar to the R-square value reported in variable-based techniques (Woodside, 2014).

Table 3: Combinations for high job satisfaction

\begin{tabular}{llll}
\hline Solutions & $\begin{array}{l}\text { Raw } \\
\text { Coverage }\end{array}$ & $\begin{array}{l}\text { Unique } \\
\text { Coverage }\end{array}$ & Consistency \\
\hline Integrating * Dominating * Compromising & 0.43 & 0.20 & 0.97 \\
Integrating * Obliging * Compromising * A Avoiding & 0.26 & 0.03 & 0.97 \\
\hline Solution Coverage & 0.46 & & \\
\hline
\end{tabular}


As shown in Table 3, two solutions with high raw consistency have been identified as associated to high job satisfaction, while no solution with a single handling style has emerged as a significant predictor of job satisfaction. Therefore, proposition two can be accepted. In line with the necessity analysis, both integrating and compromising handling styles are necessary and are present in both solutions. However, they [integrating and compromising] are insufficient and need to be complemented with either (1) a dominating style or (2) an obliging style with a low level of avoidance. Overall, the solution coverage was 0.46 . For clarity, the former group has been labelled "satisfied dominators" and the latter as "satisfied cooperatives".

\subsubsection{Further descriptive analysis: adoption of grievance handling styles}

To assess the characteristics of the employee groups, we used the "show solution cases in output" option to exhibit the characteristics of cases in each configuration (Ragin, 2017). From the sufficiency analysis, it was observed that the proportion of highly educated employees (with postgraduate degrees and more) among the satisfied dominators was higher than the share of highly educated among the satisfied cooperatives (50\% versus $5 \%$ ). In terms of experience, the share of experienced employees (i.e. individuals working in the same company for over 10 years) among the satisfied dominators group was higher than the share of experienced employees among satisfied cooperatives (50\% versus 20\%). Regarding gender, the proportion of female employees in the satisfied dominators group was slightly less than the proportion of female employees in the satisfied cooperative group (20\% versus 25\%). As for age, the percentage of older employees (over 35 years old) among satisfied dominators was slightly less than the percentage of older employees among satisfied cooperatives ( $25 \%$ versus $35 \%$ ). To assess firm type, the ratio of hotel employees who were satisfied dominators was higher than the share of hotel employees who were satisfied cooperatives (50\% versus $0 \%$ ). Therefore, it could be argued that employees with higher 
education and experience tend to be satisfied dominators, older employees and females are slightly more likely to be satisfied cooperatives, and hotel employees more probably satisfied dominators.

\section{DISCUSSION AND CONCLUSION}

Overall, the fsQCA findings confirm our two propositions and suggest that employees adopt multiple grievance handling styles to realise job satisfaction. This is an important finding as it confirms claims by Munduate et al. (1999) and Van de Vliert (1997) that individuals normally use a combination of conflict strategies rather than a single style. Also, recalling the contingency theory, these findings inform how specific work practices centered on gender, academic qualification, experience and age can be designed in the Egyptian context to manage grievance. Yet, the current study did not only test propositions but extended the ensuing understanding by uncovering two configurations of groups that address grievance in different ways. In the first group, satisfied dominators, employees exhibit an integrative and compromising style in most situations. However, when compromise is not possible, employees potentially revert to a dominating style. On the contrary, while the second group, satisfied cooperatives, also seek an integrative and comprising style, they potentially revert to an obliging style when integrating and compromising prove ineffective.

\subsection{Handling Styles and Job Satisfaction}

An integrating handling style shows concern for one's self as well as for others drawn into conflict, emphasising cooperation and allowing opposing sides to express their perspective (Rahim and Magner, 1995; Daud et al., 2013). This plays an important role in increasing employees' satisfaction and is consistent with several previous findings. The integrating handling style was found to be the most constructive of the five grievance handling styles (Trudel and Reio, 2011; Daud et al, 2013). Integrating is perceived to 
promote innovation, creativity and new ideas, which would in turn decrease employees' frustration (Daud et al., 2011). Similarly, the positive role of compromising style is consistent with most previous studies. It is perceived as a middle course approach exhibiting moderate concern for both parties [self and others] (Rahim, 2002). It provides the opportunity for parties to cooperate in order to reach a mutually satisfying decision (Rahim and Magner, 1995), and hence is likely to yield higher job satisfaction.

However, as mentioned above, it is not always possible for employees to use such approaches as, in some cases, they may revert to either a dominating or an obliging style. Accordingly, Stevahn (2004) argued that the integrating handling style is not always easy to implement. Correspondingly, Daud et al. (2013) explained that implementing an integrative way to deal with conflict generally requires a longer period of resolution, which may be impractical, whereas Weider-Hatfield and Hatfield (1995) doubted its efficacy.

In relation to satisfied dominators, it was argued that employees would need an authority-oriented approach when urgent decisions need to be made (Rahim, 2002), whereas a more flexible approach such as a compromising style could be applied in situations where resistance is anticipated from the other party (Lee, 2009). Moreover, Rahim (1983) explains that a dominating style tends to be used when the issue in question requires extensive knowledge and experience than the other side of the conflict may possess. Using a dominating style could also help employees gain others' respect. Contrastingly, a dominating approach could also present risks of escalating conflicts beyond cost limits, the deterioration of relationships and an impasse (Rubin et al., 1994), which could be offset when the dominating style is altered with a more integrative or compromising approach (Van de Vliert et al., 1999). Kochan, Katz and McKersie (1994) conclude that the combination of a dominating with a more flexible style would improve the outcome by minimizing stagnation and escalation. 
Alternatively, the satisfied cooperative is likely to revert to an obliging approach as an easy way to resolve conflicts. One side would simply concede to the other party so that the conflict is resolved (Friedman et al., 2000) and differences are minimized (Trudel and Reio, 2011). Obliging is associated to ingratiation tactics where an employee is meant to convince the other side that they think favourably of them (Friedman et al., 2000). Reverting to an obliging style could also be seen as conforming to the dynamics of face-saving and facegiving in the negotiation process (Ting-Toomey et al., 1991), where employees are more comfortable with harmony and non-confrontational situations (Boonsathorn, 2007). Yet another reason could be that some employees may be keen to maintain good relationships with powerful opponents for the long-term, and hence are ready to sacrifice short-term gains (Drory and Ritov, 1997). Nevertheless, it is important to highlight that a condition for satisfied cooperatives to be satisfied is to abstain from an avoidance style. Adopting an avoidance style results in incivility that generates lower levels of job satisfaction (Trudel and Reio, 2011).

\section{2. $\quad$ Adoption of Handling Styles}

As the results indicate, employees use a combination of grievance handling styles. Yet, why some employees would adopt a dominating oriented handling approach while others are more cooperative and obliging is an unanswered question. To this end, exploratory descriptive analysis revealed that experienced employees, with a higher degree tend to be satisfied dominators, whereas older employees and females are perhaps slightly more likely to be satisfied cooperatives.

The current finding corroborates previous studies on the factors affecting the adoption of handling styles. In this respect, it was argued that the adoption of alternative conflict handling style is largely predetermined by demographic characteristics (Gbadamosi, Ghanbari, Baghestan and Al-Mabrouk, 2014; Gunkel et al., 2016). With regard to the role of 
gender, Brewer, Mitchell and Weber (2002) showed that a masculine gender role orientation was more likely to be associated with a dominating grievance handling style, whereas Korabik et al. (1993) revealed that the obliging handling style is more positively related to employees' perceptions of effectiveness for female staff. As for the role of age and experience, our findings correspond with Daud et al.'s (2013) results indicating that experienced employees tend to adopt dominating styles. In this respect, the integrating handling style may not be effective when dealing with less experienced individuals and a dominating approach could avoid unnecessary problems (Weider-Hatfield and Hatfield, 1995). Conversely, the present findings contradict Drory and Ritov's (1997) study where experienced employees were more inclined towards an obliging handling style. According to the authors, experienced employees tend to become less dominating, more obliging and more avoiding as they value longer-term goals over short-term gains. This is also confirmed by the tendency of experienced individuals to lean towards avoiding and compromising styles (Labrague and McEnroe-Petitte, 2017). Such contrasting findings could however be explained by the setting of the current study. Egypt is ranked relatively low in long-term orientation (Hofstede and Minkov, 2010), which can explain the tendency of experienced employees to choose a dominating approach since they may not be oriented towards longerterm goals. As for the influence of educational level, although very few extant work investigate this factor, our findings could be interpreted that further education confers a level of confidence to employees that would encourage them to channel a more dominating style.

In summary, it could be argued that in the Egyptian tourism sector, employees tend to espouse more than one grievance handling style to maintain job satisfaction. More importantly, two profiles of grievance handling styles have been established, and both tend to exhibit high job satisfaction. Labelled as satisfied dominant and satisfied cooperative, the adoption of either approach by employees is potentially determined by their age, gender, 
experience and academic qualification. The complexity approach adopted in this study could clarify conflicting findings reported in the literature. For instance, while previous studies questioned the relevance of the dominating style for job satisfaction (e.g. Weider-Hatfield and Hatfield, 1995), the present study shows that the latter can still be effective when combined with the integrative and compromising styles. Similarly, the present findings could reconcile conflicting results regarding the role of an integrative handling style. In fact, although studies support its efficacy (Rahim, 1983; Trudel and Reio, 2011), other studies seem to suggest otherwise (Stevahn, 2004; Daud et al., 2013). Here, we argue that an integrative style can only be effective when combined either with a dominating or obliging style, depending on the situation. In short, the present findings confirm that universal grievance handling styles are ineffective. Rather, balanced and more flexible approaches that can be adjusted to suit peculiar situations should be embraced.

\section{IMPLICATIONS}

The findings of this study hold several important implications for tourism practitioners. Employees are organisations' most important assets, especially in the tourism sector. Heavy workloads in tourism organisations in Egypt constitute a critical factor for low job satisfaction and is a major source of conflict. In turn, job satisfaction is a key driver for service quality and customer satisfaction (Yeh, 2013). Therefore, effective conflict handling strategies yield collective action and promote employees' willingness to participate in daily operations (Lee et al., 2009).

The configuration approach adopted in this study suggested that an effective grievance handling approach is one that involves a mixture or combination of various styles. The fsQCA analysis highlighted the importance of aligning multiple styles to achieve satisfaction. Furthermore, the study uncovered an equifinality phenomenon and highlighted at least two distinct routes that can result in higher employee satisfaction amongst Egyptian 
tourism organisations, depending on employee characteristics. More importantly, the current results reveal that although certain handling styles (such as dominating or obliging) have been typically considered as potentially harmful, they can become effective when combined with other styles and in specific circumstances. In particular, the integrating and compromising styles have been found to be key ingredients in such combinations, yet insufficient to achieve success.

Following these findings, it is important to stress that the various handling styles are complementary and no single option is optimal. Therefore, the ability to master the deployment of various handling styles when managing conflicts is a key skill to be developed by employees and managers in the tourism sector. Employees/supervisors should be able to identify and apply the optimal mix of styles in accordance with the situation being handled. In this regard, we suggest that a resolution strategy involving integration and compromise could be used at the initial phase of conflict, whereas domination or obligation could be used as the "last resort". Here, the choice would depend on individuals' experience and knowledge of the issue. When employees/supervisors feel they possess sufficient experience and knowledge in relation to the matter in question, a dominating approach should be adopted as this will likely lead to a higher satisfaction. In contrast, when employees/supervisors lack experience and knowledge in the subject matter, an obliging style should be adopted to avoid negative outcomes. However, an obliging style should not be accompanied with an avoiding approach, as this will have the reverse effect. Executing the right combinations to generate job satisfaction will equip both employees and managers in tourism with the skills and flexibility to deploy relevant grievance handling styles that are more likely to satisfy opposing parties.

In the final contextual analysis, it is worth mentioning that in Egypt, courses on conflict management are almost non-existent. Undertaking basic training in grievance 
management would impart managers and employees with the skills required for early and effective conflict resolution. Simulation exercises could be a part of such training in Egypt as there is evidence of the positive influence of behavioural modelling on grievance handling styles (Pines et al., 2014; Waite and McKinney, 2014). Critical focus is needed on training tourism professionals to develop their skills in using the right mix of handling approaches when managing conflicts. Training could help individuals understand why and how they are predisposed to particular styles of grievance handling. Consequently, we call on training institutions in Egypt to reflect on these findings in the design of tailored courses for conflict management in tourism.

In terms of limitations, we acknowledge the following: The additional analysis conducted in this research to identify the factors affecting the adoption of conflict handling styles was mainly descriptive, therefore should be considered exploratory. Moreover, due to the non-probability nature of the sample and the relative imbalance in terms of hotels and travel agency respondents, the representativeness of the results should be considered with caution when making generalizations. Our findings are by no means generalizable to all Egyptian employees and hence we call for further studies to validate our propositions in different contexts. Likewise, measures used in this study were all perception based Likert scales. Despite their popularity in management studies and their efficiency, these scales do pose limitations in cross-cultural research (Taras et al., 2009). Evidence has shown that response style when using Likert scales can be affected by the cultural background of the respondents (Harzing, 2006). For instance, extreme responses are prevalent in some cultures as opposed to others. This is due to the "systematic tendency to over express agreement or disagreement" (Taras et al., 2009: 366). Hence, this could have been the case here as scores for some of the variables were inclined towards higher values. Lastly, the cross-sectional nature of the data utilised in this study allows the researchers to capture associations rather 
than causality. We call further studies to complement cross-sectional methods with longitudinal studies so that causal relationships can be assessed with greater confidence.

\section{APPENDIX Survey Questions}

\section{Integrating Grievance Style}

I try to investigate an issue with my supervisor to find a solution acceptable to us.

I try to integrate my ideas with those of my supervisor to come up with a decision jointly.

I try to work with my supervisor to find solutions to a problem, which satisfy our expectations.

I exchange accurate information with my supervisor to solve a problem together.

I try to bring all our concerns out in the open so that the issues can be resolved in the best possible way.

I collaborate with my supervisor to come up with decisions acceptable to us.

I try to work with my supervisor for a proper understanding of a problem.

\section{Obliging Grievance Style}

I generally try to satisfy the needs of my supervisor.

I usually accommodate the wishes of my supervisor.

I give in to the wishes of my supervisor.

I usually allow concessions to my supervisor.

I often go along with the suggestions of my supervisor.

I try to satisfy the expectations of my supervisor.

\section{Dominating Grievance Style}

I use my influence to get my ideas accepted.

I use my authority to make a decision in my favor.

I use my expertise to make a decision in my favor.

1 am generally firm in pursuing my side of the issue.

I sometimes use my power to win a competitive situation.

\section{Avoiding Grievance Style}

I attempt to avoid being "put on the spot" and try to keep my conflict with my supervisor to myself.

I usually avoid open discussion of my differences with my supervisor.

I try to stay away from disagreement with my supervisor. 
I avoid an encounter with my supervisor.

I try to keep my disagreement with my supervisor to myself in order to avoid hard feelings. I try to avoid unpleasant exchanges with my supervisor.

\section{Compromising Grievance Style}

I try to find a middle course to resolve an impasse.

I usually propose a middle ground for breaking deadlocks.

I negotiate with my supervisor so that a compromise can be reached.

I use "give and take" so that a compromise can be made.

\section{Job Satisfaction}

At this very moment, I am enthusiastic about my work.

Right now, I feel fairly satisfied with my present job.

At present, I am enjoying every minute at work

At this moment, I am finding real enjoyment in my work.

Right now, I consider my job rather pleasant 


\section{REFERENCES}

Abbasi, B., Gul, A. \& Senin, A. (2018). Conflict Management Style Preference: Does National Culture Matter? Advanced Science Letters, 24(6), 4353-4357.

Abou-Shouk, M., Megicks, P. \& Lim, W. (2013). Perceived benefits and e-commerce adoption by SME travel agents in developing countries: Evidence from Egypt. Journal of Hospitality \& Tourism Research, 37(4), 490-515.

Ahl, H. (2006). Why research on women entrepreneurs needs new directions. Entrepreneurship theory and practice, 30(5), 595-621.

Alexander, D. (1995). Conflict management styles of administrators in schools for the deaf: Teacher perceptions of job satisfaction. Unpublished doctoral dissertation, Gallaudet University, United States.

Attallah, N. F. (2015). Evaluation of perceived service quality provided by tourism establishments in Egypt. Tourism and Hospitality Research, 15(3), 149-160.

Awang, K., Aziz, Y. \& Samdin, Z. (2015). The growth of micro, small and medium-sized hotel enterprises: the hoteliers' perspectives. Journal of Technology Management and Business, 2(1), 34-47.

Ayub, N., AlQurashi, S., Al-Yafi, W. \& Jehn, K. (2017). Personality traits and conflict management styles in predicting job performance and conflict. International Journal of Conflict Management, 28(5), 671-694.

Baum, T. (2015). Human resources in tourism: Still waiting for change? - A 2015 reprise. Tourism Management, 50, $204-212$.

Bean, R. (2004). Comparative Industrial Relations: An Introduction to Cross-National Perspectives. 2nd Edition. London: Routledge.

Bérubé, N., Donia, M., Gagné, M., Houlfort, N. \& Koestner, R. (2007). Validation of the satisfaction with work scale. In ASAC (Vol. 28, No. 5).

Boonsathorn, W. (2007). Understanding conflict management styles of Thais and Americans in multinational corporations in Thailand. International Journal of Conflict Management, 18(3), 196-221.

Brewer, N., Mitchell, P. \& Weber, N. (2002). Gender role, organizational status, and conflict management styles. International Journal of Conflict Management, 13(1), 78-94.

Brown, L., \& Osman, H. (2017). The female tourist experience in Egypt as an Islamic destination. Annals of Tourism Research, 63, 12-22.

Brummer, V., Herbes, C. \& Gericke, N. (2017). Conflict Handling in Renewable Energy Cooperatives (RECs): Organizational Effects and Member Well-Being. Annals of Public and Cooperative Economics, 88(2), 179-202.

Chan, J., Sit, E. \& Lau, W. (2014). Conflict management styles, emotional intelligence and implicit theories of personality of nursing students: A cross-sectional study. Nurse Education Today, 34(6), 934-939. 
Chan, K., Huang, X. \& Ng, P. (2008). Managers' conflict management styles and employee attitudinal outcomes: The mediating role of trust. Asia Pacific Journal of Management, 25(2), 277-295.

Chen, X., Zhao, K., Liu, X. \& Dash W. (2012). Improving employees' job satisfaction and innovation performance using conflict management. International Journal of Conflict Management, 23(2), 151-172.

Chow, I. \& Liu, S. (2009). The effect of aligning organizational culture and business strategy with HR systems on firm performance in Chinese enterprises. The International Journal of Human Resource Management, 20(11), 2292-2310.

Coviello, N. E., \& Jones, M. V. (2004). Methodological issues in international entrepreneurship research. Journal of Business Venturing, 19(4), 485-508.

Daly, T., Lee, A., Soutar, G. \& Rasmi, S. (2010). Conflict-handling style measurement: a best-worst scaling application. International Journal of Conflict Management, 21(3), 281-308.

Daud, Z., Isa, M., Nor, W. \& Zainol, Z. (2013). Do we need to train our managers in handling grievances? International Journal of Business and Social Science, 4(3), 123-135.

Delery, J. \& Doty, H. (1996) Modes of theorizing in strategic human resource management: tests of universality, contingency and configurational performance predictions. Academy of Management Journal, 39(4), 802-35.

Drory, A., \& Ritov, I. (1997). Effects of work experience and opponent's power on conflict management styles. International Journal of Conflict Management, 8(2), 148-161.

Egypt Today (2018). Egypt is the fastest growing tourist destination: UNWTO. Available at: http://www.egypttoday.com/Article/9/57248/Egypt-is-the-fastest-growing-touristdestination-UNWTO. [Accessed on: 14th October 2018].

Egyptian Tourism Chamber (2016). Second issue, April. Cairo, Egypt.

Erkutlu, H., \& Chafra, J. (2015). The mediating roles of psychological safety and employee voice on the relationship between conflict management styles and organizational identification. American Journal of Business, 30(1), 72-91.

European Training Foundation (2010) Women and Work in Egypt. Torino: European Training Foundation.

Fiss, P., Sharapov, D. \& Cronqvist, L. (2013). Opposites attract? Opportunities and challenges for integrating large-N QCA and econometric analysis. Political Research Quarterly, 66(1), 191-198.

Friedman, R., Tidd, S., Currall, S. \& Tsai, J. (2000). What goes around comes around: The impact of personal conflict style on work conflict and stress. International Journal of Conflict Management, 11(1), 32-55.

Gbadamosi, O., Ghanbari-Baghestan, A. \& Al-Mabrouk, K. (2014). Gender, age and nationality: assessing their impact on conflict resolution styles. Journal of Management Development, 33(3), 245-257. 
Gunkel, M., Schlaegel, C. \& Taras, V. (2016). Cultural values, emotional intelligence, and conflict handling styles: A global study. Journal of World Business, 51(4), 568-585.

Hartman, R. \& Crume, A. (2014). Educating nursing students in team conflict communication. Journal of Nursing Education and Practice 4 (11), 107.

Harzing, A. W. (2006). Response styles in cross-national survey research: A 26-country study. International Journal of Cross Cultural Management, 6(2), 243-266.

Havenga, W. \& Visagie, J. (2006). Interpersonal conflict-handling styles used in public and private sector organizations: A comparative study. SA Journal of Industrial Psychology, 32(1), 60-65.

Hofstede, G., \& Minkov, M. (2010). Long-versus short-term orientation: new perspectives. Asia Pacific business review, 16(4), 493-504.

Isa, M. \& Noor, W. (2011) The influence of heads of department personalities on the selection of grievance handling styles. International Journal of Humanities and Social Science. 1(7), 241-252.

Jehn, K. \& Bendersky, C. (2003). Intragroup conflict in organizations: A contingency perspective on the conflict-outcome relationship. Research in organizational behavior, 25(2003), 187-242.

Jensen, S. M., \& F. Luthans. (2006). Entrepreneurs as Authentic Leaders: Impact on Employees' Attitudes. Leadership \& Organization Development Journal 27 (8): 64666.

Judge, T., Locke, E., Durham, C. \& Kluger, A. (1998). Dispositional effects on job and life satisfaction: The role of core evaluations. Journal of applied psychology, 83(1), 17.

Kattara, H. \& El-Said, O. (2013). Innovation strategies: The implementation of creativity principles in Egyptian hotels. Tourism and Hospitality Research, 13(3), 140-148.

Kattara, H. (2005) Career challenges for female managers in Egyptian hotels. Journal of Contemporary Hospitality Management, 17(2/3), 238-251.

Kent, R. (2015). Analysing Quantitative Data: Variable-based and Case-based Approaches to Non-experimental Datasets. London: SAGE Publications.

Kilmann, R. \& Thomas, K. (1977). Developing a forced-choice measure of conflict-handling behavior: The" MODE" instrument. Educational and psychological measurement, 37(2), 309-325.

Kochan, T., Katz, H. \& McKersie, R. (1994). The Transformation of American Industrial Relations (First ILR Press Edition) Ithaca, New York, ILR Press.

Korabik, K., Baril, G. L., \& Watson, C. (1993). Managers' conflict management style and leadership effectiveness: The moderating effects of gender. Sex Roles, 29(5-6),405420. 
Krautscheid, L., Luebbering, C. \& Krautscheid, B. (2017). Conflict-handling styles demonstrated by nursing students in response to microethical dilemmas. Nurs. Educ. Perspect. 38 (3), 143-145.

Labrague, L. \& McEnroe-Petitte, D. (2017). An integrative review on conflict management styles among nursing students: Implications for nurse education. Nurse education today, 59, 45-52.

Labrague, L., Al Hamdan, Z. \& McEnroe-Petitte, D. (2018). An integrative review on conflict management styles among nursing professionals: implications for nursing management. Journal of Nursing Management, 2008(00), 1-16.

Lee, K. (2009). An examination between the relationship of conflict management styles and employees' satisfaction with supervision. International Journal of Business and Management, 3(9), 11.

Lee, T., Riley, M. \& Hampton, M. (2010) Conflict and Progress. Annals of Tourism Research, 37(2), 355-376.

Li, P., Joppe, M. \& Meis, S. (2016) Human resource management impacts on labour productivity in tourism. Tourism Economics, 23(5), 1028-1041.

Liu, Z; Law, R. \& Zhong, S. (2017) Exploring human resource challenges in China's tourism industry. Tourism Recreation Research, 42 (1), 72 - 83.

McKersie, R., \& Cutcher-Gershenfeld, J. (2009). Labor-management relations: understanding and practicing effective negotiations. Negotiation Journal, 25(4), 499514.

Meng, Y., Yu, H., Ma, Z. \& Yang, Z. (2018). The impact of young Chinese employees' notions of work on conflict management styles: An explorative study. International Journal of Conflict Management, 29(3), 306-326.

Messarra, L., Karkoulian, S. \& El-Kassar, A. (2016). Conflict resolution styles and personality: The moderating effect of generation $\mathrm{X}$ and $\mathrm{Y}$ in a non-Western context. International journal of productivity and performance management, 65(6), 792-810.

Michaelson, R. (2016). Egypt holidays: Egypt's tourism industry is still reeling but hope is on the horizon. The Guardian, 21st October 2016. Available at: https://www.theguardian.com/travel/2016/oct/21/egypt-tourism-industry-plagued-bylack-of-visitors. [Accessed on 15th December 2018].

Mlozi, S., \& Pesämaa, O. (2013). Adventure tourist destination choice in Tanzania. Current Issues in Tourism, 16(1), 63-95.

Montoro-Rodriguez, J. \& Small, J. (2006). The role of conflict resolution styles on nursing staff morale, burnout, and job satisfaction in long-term care. Journal of aging and health, 18(3), 385-406.

Munduate, L., Ganaza, J., Peiro, J. \& Euwema, M. (1999). Patterns of styles in conflict management and effectiveness. International Journal of Conflict Management, 10(1), $5-24$. 
Nayak, T., Sahoo, C. \& Mohanty, P. (2017). Impact of HR interventions on quality of work life: evidence from healthcare units. International Journal of Indian Culture and Business Management, 14(2), 214-236.

Nicotera, A. (1994). The use of multiple approaches to conflict: A study of sequences. Human Communication Research, 20(4), 592-621.

OECD Database, (2016). Enterprises and employment tourism, Country: Egypt. [Online] Available at https://stats.oecd.org/Index.aspx?ThemeTreeId=10\&DatasetCode=tourism_entr_empl [Accessed 25/10/2018].

Ordanini, A., Parasuraman, A. \& Rubera, G. (2014). When the recipe is more important than the ingredients: A qualitative comparative analysis (QCA) of service innovation configurations. Journal of Service Research, 17(2), 134-149.

Pines, E., Rauschhuber, M., Cook, J., Norgan, G., Canchola, L., Richardson, C. \& Jones, M. (2014). Enhancing resilience, empowerment, and conflict management among baccalaureate students: outcomes of a pilot study. Nurse Educ. 39 (2), 85-90

Ragin, C. (2000). Fuzzy-set social science. Chicago: University of Chicago Press.

Ragin, C. (2009). Qualitative comparative analysis using fuzzy sets (fsQCA). In B. Rihoux, \& C. Ragin (Eds.), In configurational comparative methods (pp. 87e122). Thousand Oaks, CA: Sage.

Ragin, C. (2017). User's Guide to Fuzzy-Set/Qualitative Comparative Analysis 3.0. Irvine, California: Department of Sociology, University of California.

Ragin, C. and Davey, S. 2016. Fuzzy-Set/Qualitative Comparative Analysis 3.0. Irvine, California: Department of Sociology, University of California.

Rahim, M. \& Buntzman, G. (1989). Supervisory power bases, styles of handling conflict with subordinates, and subordinate compliance and satisfaction. The Journal of Psychology, 123(2), 195-210.

Rahim, M. \& Magner, N. (1995). Confirmatory factor analysis of the styles of handling interpersonal conflict: First-order factor model and its invariance across groups. Journal of applied psychology, 80(1), 122-132.

Rahim, M. (1983). A measure of styles of handling interpersonal conflict. Academy of Management journal, 26(2), 368-376.

Rahim, M. (2002). Toward a theory of managing organizational conflict. International journal of conflict management, 13(3), 206-235.

Rubin, J., Pruitt, D. \& Kim, S. (1994). Social conflict: Escalation, stalemate, and settlement. New York: McGraw-Hill.

Rubin, K. \& Brown, I. (1975). A life-span look at person perception and its relationship to communicative interaction. Journal of Gerontology, 30(4), 461-468. 
Saeed, T., Almas, S., Anis-ul-Haq, M. \& Niazi, G. (2014). Leadership styles: relationship with conflict management styles. International Journal of Conflict Management, 25(3), 214-225.

Salem, I. (2015). Transformational leadership: Relationship to job stress and job burnout in five-star hotels. Tourism and Hospitality Research, 15(4), 240-253.

Saunders, M., lewis, P. \& Thornhill, A. (2016). Research Methods for business students. Pearson Professional Limited, England, UK.

Simons, T. \& Enz, C. (1995). Motivating hotel employees: beyond the carrot and the stick. Cornell Hotel and Restaurant Administration Quarterly, 36(1), 20-27.

Stevahn, L. (2004). Integrating conflict resolution training into the curriculum. Theory into Practice, 43(1), 50-58.

Tabassi, A, Bryde, D., Abdullah, A. \& Argyropoulou, M. (2017). Conflict Management Style of Team Leaders in Multi-Cultural Work Environment in the Construction Industry. Procedia Computer Science, 121, 41-46.

Taras, V., Rowney, J. \& Steel, P. (2009). Half a century of measuring culture: Review of approaches, challenges, and limitations based on the analysis of 121 instruments for quantifying culture. Journal of International Management, 15(4), 357-373.

Thomas, K. \& Kilmann, R. (1974) Thomas-Kilmann Conflict Mode Instrument. New York: Xicom Inc.

Thomas, K. \& Schmidt, W. (1976). A survey of managerial interests with respect to conflict. Academy of Management journal, 19(2), 315-318.

Thomas, K., Fann, G. \& Schaubhut, N. (2008). Conflict styles of men and women at six organization levels. International Journal of Conflict Management, 19(2), 148-166.

Ting-Toomey, S., Gao, G., Trubisky, P., Yang, Z., Soo, H., Lin, S. \& Nishida, T. (1991). Culture, face maintenance, and styles of handling interpersonal conflict: A study in five cultures. International Journal of conflict management, 2(4), 275-296.

Trudel, J., \& Reio, T. (2011). Managing workplace incivility: The role of conflict management styles-antecedent or antidote?. Human Resource Development Quarterly, 22(4), 395-423.

Van de Vliert, E. (1997). Complex interpersonal conflict behaviour: Theoretical frontiers. Psychology Press. Tylor and Francis Group.

Van De Vliert, E., Euwema, M. \& Huismans, S. (1995). Managing conflict with a subordinate or a superior: Effectiveness of conglomerated behavior. Journal of applied Psychology, 80(2), 271-283.

Van de Vliert, E., Nauta, A., Giebels, E. \& Janssen, O. (1999). Constructive conflict at work. Journal of Organizational Behavior, 20(4), 475-491.

Vis, B. (2012). The comparative advantages of fsQCA and regression analysis for moderately large-n analyses. Sociological Methods and Research, 41(1), 168-198. 
Wagemann, C. \& Schneider, C. (2010). Standards of Good Practice in Qualitative Comparative Analysis (QCA) and Fuzzy-Sets. Comparative Sociology 9(3), 1-35.

Waite, R. \& McKinney, N. (2014). Enhancing conflict competency. Association of Black Nursing Faculty in Higher Education. 25 (4), 123-128.

Weider-Hatfield, D. \& Hatfield, J. (1995). Relationships among conflict management styles, levels of conflict, and reactions to work. The Journal of social psychology, 135(6), 687-698.

Woodside, A. \& Zhang, M. (2012). Identifying x-consumers using causal recipes: "Whales" and "jumbo shrimps" casino gamblers. Journal of Gambling Studies, 28(1), 13-26.

Woodside, A. (2014). Embrace perform model: Complexity theory, contrarian case analysis, and multiple realities. Journal of Business Research, 67(12), 2495-2503.

World Tourism Organisation (2018) UNWTO Tourism Highlights. Madrid: United Nations World Tourism Organisation.

WTTC (2017). Travel and Tourism Economic Impact 2017 Egypt. Available at: https://www.wttc.org/-/media/files/reports/economic-impact-research/countries2017/egypt2017.pdf. Accessed on: 27th March 2018.

Yang, J., Wan, C. \& Fu, Y. (2012). Qualitative examination of employee turnover and retention strategies in international tourist hotels in Taiwan. International Journal of Hospitality Management, 31(3), 837-848.

Yeh, C. (2013). Tourism involvement, work engagement and job satisfaction among frontline hotel employees. Annals of Tourism Research, 42, 214-239.

Yolal, M., Chi, C. \& Pesämaa, O. (2017). Examine destination loyalty of first-time and repeat visitors at all-inclusive resorts. International Journal of Contemporary Hospitality Management, 29(7), 1834-1853.

Yuan, W. (2010). Conflict management among American and Chinese employees in multinational organizations in China. Cross Cultural Management: An International Journal, 17(3), 299-311.

Zhang, J., Li, H., Luo, X. \& Warkentin, M. (2017). Exploring the Effects of the Privacy-Handling Management Styles of Social Networking Sites on User Satisfaction: A Conflict Management Perspective. Decision Sciences, 48(5), 956-989.

Zhang, Z. \& Wei, X. (2017). Superficial harmony and conflict avoidance resulting from negative anticipation in the workplace. Management and Organization Review, 13(4), 795-820. 